\title{
تداعيات خروج بريطانيا من الاتحاد الأورويي على أيرلندا الشمالية وويلز واسكتلندا
}

\section{The implications of Brexit On Northern Ireland, Wales and Scotland}

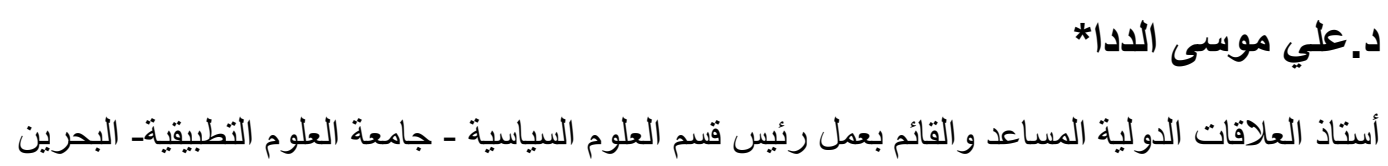

Availible online at https://www.maspolitiques.com/ojs/index.php/ajps/article/view/216

ملخص:

أظهرت نتائج الاستفتاء الثامل بشأن عضوية المملكة المتحدة في الاتحاد الأوروبي، والتي كانت نتائجه بتصويت 52\% من البريطانيين بانسحاب بريطانيا من الاتحاد، بأن المشروع الأوروبي الذي يُفهم على أنه عملية تكامل سياسي داخل الاتحاد الأوروبي، قد أصبحت غير مستقرة وغير آمنة، حيث رافق ذلك بدأ الأزمة الاقتصادية وأزمات جديدة مثل الهجرة والسوق المشتركة، عدا عن تفكير بعض الدول في الانفصال عن المملكة المتحدة. كما أصبحت هناك نقانشات جديدة حول المشروع الأوروبي ومدى استقراره مستقبلً، ذلك ان هذا القرار البريطاني يؤثز على الاتحاد الأوروبي بشكل كبير وعلى شروط عمل الاتحاد ومستقبله، كما أن خروج بريطانيا سيضر بالتماسك والنقة والسمعة الدولية للاتحاد الأوروبي. ولا شك بأن الوضع الحالي هو أخطر أزمة في ناريخ التكامل الأوروبي، حيث أدى التصويت لصالح "خروج بريطانبا من الاتحاد الأوروبي" إلى إرسال صدمات الى جميع أنحاء العالم وخاصة القارة الأوروبية، وهز الأسواق المالية وإعادة إحياء المناقثات العالمية حول قابلية الاتحاد الأوروبي للاستمرار على المدى الطويل. كلمات مفتاحية: بريطانيا، الاتحاد الأوروبي، أسكتلندا، أيرلندا، ويلز مقدمة:

مرت علاقات بربطانيا والاتحاد الأوروبي بمحطات بارزة انطلقت عام 1961م، بتقديم لندن ترشيحها لعضوية المجموعة الاقتصادية، وانتهت يوم 23 يونيو 2016م بتصويت 52\% من البريطانيين لصالح الخروج من حضن الاتحاد. ولقد أدى التصويت على خروج بريطانيا من الاتحاد الأوروبي الى تسلبط الضوء أيضًا على الانقسامات العميقة التي تتخطى الخطوط التقليدية للأحزاب في السياسة البريطانية، وكان التصويت على خروج بريطانيا من الاتحاد الأوروبي بمثابة تذكير قوي بالقوة المطلقة للتقاليد الأوبية المتشددة في بربطانيا والانقسامات الحادة بين النخبة السياسية في البلاد حول علاقة بربطانيا بأوروبا.

\footnotetext{
*dr.alidada@yahoo.com
} 
وعلى مستوى أعمق، يجب أن يُنظر إلى خروج بريطانيا من الاتحاد الأوروبي أيضًا على أنه أحد أعراض أنس

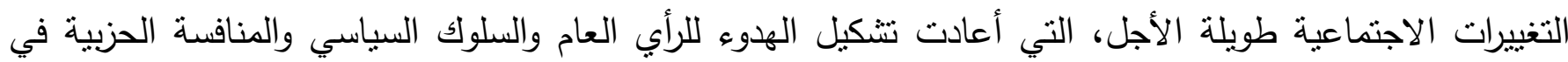
المملكة المتحدة، وكذللك في الديمقراطيات الغربية الأخرى.

نحاول من خلال هذه الدراسة توضيح الأسباب الرئيسة وراء التصويت لصالح خروج بريطانيا من الاتحاد الأوروبي، مع إبراز اهتمام خاص لتحليل ما لاح في الأفق من وجود أزمة تنعلق بموقف ومصير كل من أيرلندا

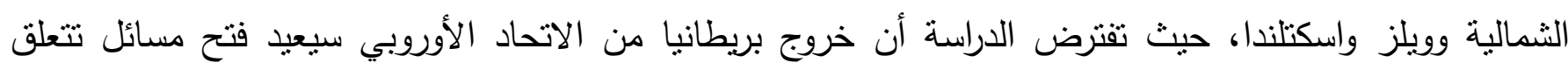
بانفصال هذه الدول، خاصة وأنها قد شهدت في أوقات مختلفة ظهور حركات تدعو الى انفصالها عن بريطانيا

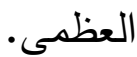

ولأننا بصدد تحليل قرار المملكة المتحدة بالخروج من الاتحاد الأوروبي، وتوسيع فهم العوامل المؤثرة في هذا القرار، ومناقثنة موقف كل من أيرلندا الثمالية وويلز واسكتلندا حول القرار البريطاني للإنسحاب من الاتحاد الأوروبي، والتداعيات الناجمة عن ذللك، فإن إثكالية هذه الدراسة انطلقت من طرحنا لسؤالين أساسيين: ماهي دوافع بريطانيا للانسحاب من الاتحاد الأوروبي؟ وما هي تداعيات ذلك على كل من اسكتلندا وايرلندا الثمالية وويلز؟ وفي سعينا للإجابة على هذين السؤالين، وجدنا من المناسب الاعتماد على المنهج الوصفي التحليلي لقدرته على وصف حيثيات الدراسة كما توجد على أرض الواقع ومن ثم المساهمة في تحليل الأبعاد والنتائج في آن معًا، خاصة ما تعلق بأسباب قرار خروج بريطانيا من الاتحاد الأوروبي ونتائج ذلك على موقف كل من أسكتلندا وأيرلندا الثمالية وويلز من هذا القرار.

\section{أولاً: العلاقة البريطانية- الأورويية:}

يرتكز تاريخ العلاقة بين بريطانيا والاتحاد الاوروبي على ما يسمى بثنائية النتاقض. فمن جهة هناك تاريخ طويل وموثق من العداء وعدم الثقة بين بريطانيا والاتحاد الاوروبي، ومن جهة أخرى دخلت الحكومات البريطانية المتتالية بنشاط محموم في عملية الاندماج الاوروبي، بغية تأمين مصالح بريطانيا السياسية والاقتصادية. هذه الثنائية خلقت

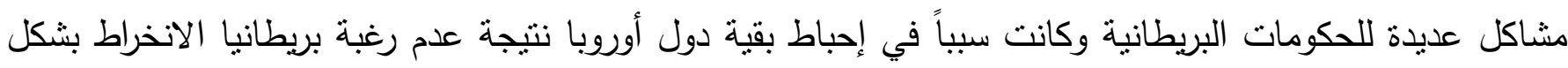
كامل في مسيرة الوحدة الأوروبية 1.

1ـ محمد مطاوع، تحديات الخروج و البقاء:تعقيدات العلاقة بين بريطانيا والاتحاد الأوروبي، السياسة الدولية، العدد 203، يناير 2016م، ص 45 
كما عرقل الموقف البريطاني استكمال الاندماج الأوروبي في عدة مناسبات، ولطالما اعتبرت بريطانيا نفسها، ولا سيما المحافظين فيها، دولةً أطلسيةً أكثر منها أوروبية، متخذة سياسة اقتصادية وخارجية أكثر قربًا من الولايات المتحدة. لكن ذللك لم يمنعها من التطلع لتحقيق مصالح كبرى سياسية واقتصادية من خلال الانضمام للنادي الأوروبي من ناحية، والاستمرار في تأدية دورها التاريخي في منع هيمنة فرنسية - ألمانية مشتركة على القرار الأوروبي، من

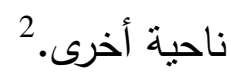

ومنذ التوقيع على اتفاقية ماستريخت المؤسسة للاتحاد الأوروبي عام 1992م، تعالت في بريطانيا أصواتُ تتساءل عن مستقبل العلاقة مع الاتحاد الأوروبي. وعلى الرغم من الضغوط التي مورست على رؤساء الحكومات البريطانية

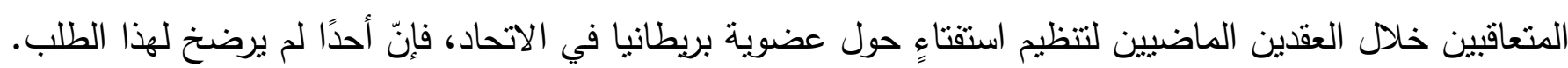
ووقع التحول الجوهري عندما عاد المحافظون إلى الحكم بعد غياب استمر 13 عامًا، إذ طرحت حكومة رئيس الوزراء،

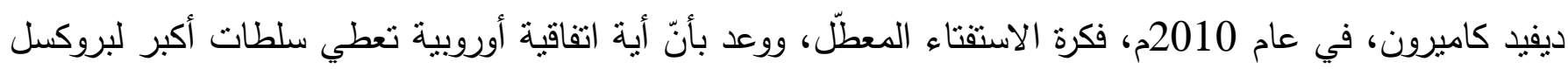
على حساب الدول الأعضاء، يجب أن يتم التصديق عليها من خلال التصويت أو استقتاء شعبي، ومع بداية عام 2013م، ذهب كاميرون خطوة أبعد عندما أعلن عزم حكومته إجراء استفتاء على البقاء أو الخروج من الاتحاد الأوروبي.

في عام 2012م كان قد رفض رئيس الوزراء ديفيد كاميرون، دعوات إجراء استفتاء حول عضوية المملكة المتحدة

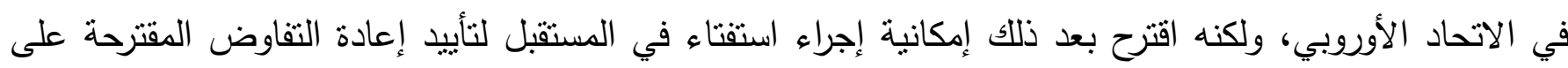

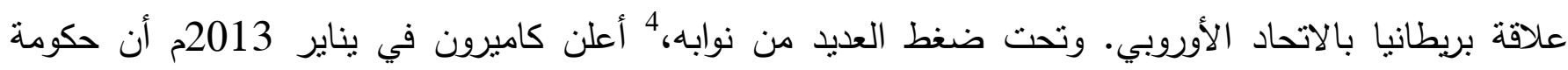

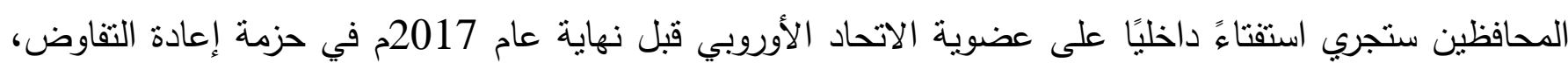
إذا ما ثم انتخابه في الانتخابات العامة في 7 مايو 2015م، وتم تضمين هذا في بيان حزب المحافظين للانتخابات. وعند فوز حزب المحافظين في الانتخابات بأغلبية، نم تقديم قانون استقتاء الاتحاد الأوروبي لعام 2015م إلى البرلمان للتمكين من إجراء الاستفتاء. ولقد فضل كاميرون البقاء في الاتحاد الأوروبي الذي تم إصلاحه وسعى إلى لى

${ }^{2}$ Dąbrowski, M. (2016). The future of the European Union: towards a functional federalism. Acta Oeconomica, 66(1). doi:10.1556/032.2016.66.S1.2.

${ }^{3}$ David Cameron, "EU speech at Bloomberg," Bloomberg, 23/01/2013, accessed on 30/6/2016, at: http://bit.ly/LBzZU4

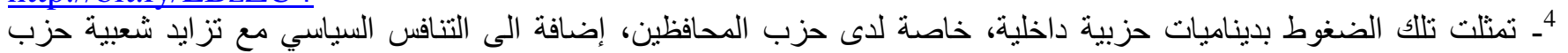

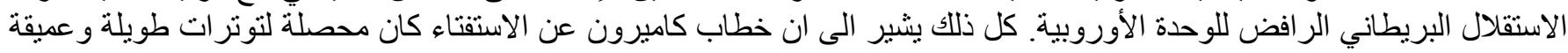

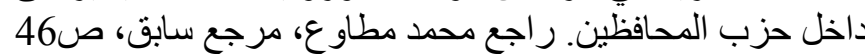

5 Stern, S. (2018) 'Theresa May's handling of Brexit is a classic case of bad leadership', The Conversation, 12 December, available at https://theconversation.com/theresa-mays-handling-of-brexit-isa-classic-case-of-bad-leadership-108646. 
إعادة التفاوض بشأن أربع نقاط أساسية هي: حماية السوق الموحدة للبلدان غير الأوروبية، والحد من "الروتين"، وإعفاء بريطانيا من "الاتحاد الأقرب"، وتقييد هجرة الاتحاد الأوروبي.

وفي سبتمبر 2015م أظهرت استطلاعات الرأي وجود أغلبية واضحة لصالح البقاء في الاتحاد الأوروبي. كما أظهرت أن الدعم سيتراجع إذا ما استمرت أزمة اللاجئين والمهاجرين غير الثرعيين في التذهور في أوروبا، وإذا لم

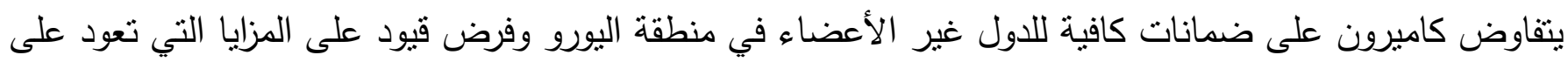
مواطني الاتحاد الأوروبي.6

تم الإعلان عن نتائج إعادة التفاوض في فبراير 2016م، وتم الاتفاق على بعض القيود على الفوائد أثناء العمل للمهاجرين الجدد في الاتحاد الأوروبي، ولكن قبل تطبيقها ينعين على بلد مثل المملكة المتحدة الحصول على إذن من الدفوضية الأوروبية ومن ثم المجلس الأوروبي. وفي خطابه أمام مجلس العموم في 22 فبراير 2016م، أعلن كاميرون تاريخ استفتاء 23 يونيو 2016م وعلق على تسوية إعادة التفاوض، كما تحدث عن نية إطلاق عملية المادة

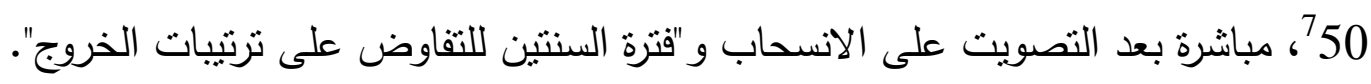

ولقد أدلى البريطانيون في 23 يونيو 2016م بأصواتهم حول عضوية بلادهم في الاتحاد الأوروبي، في استفتاءٍ دعا إليه رئيس الوزراء البريطاني ديفيد كاميرون. وشارك في الاستفتاء ما يقارب 30 مليون ناخب، وجاءت نتائج

${ }^{6}$ Clausing, K.A. and Dorobantu, C.L. (2005), "Re-entering Europe: Does European Union candidacy boost foreign direct investment?", The Economics of Transition. Vol.13, No1, pp.77-103.

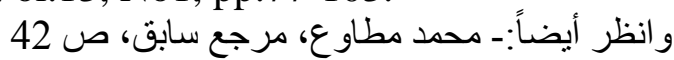

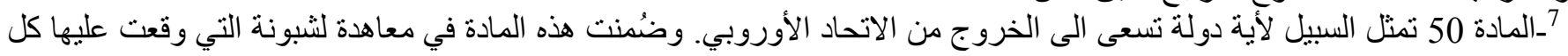

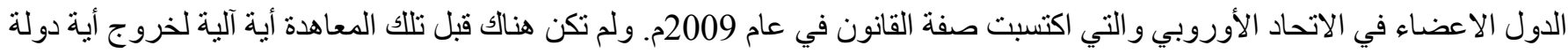

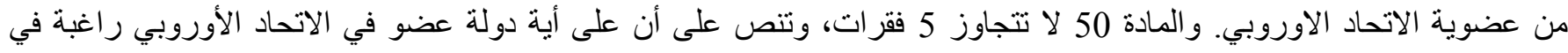

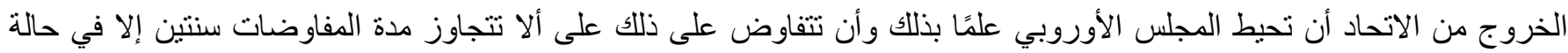

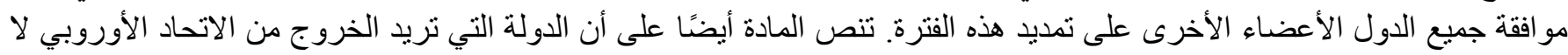

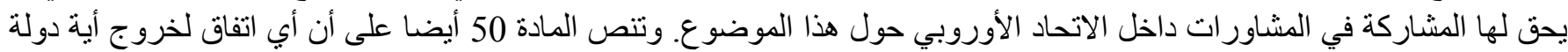

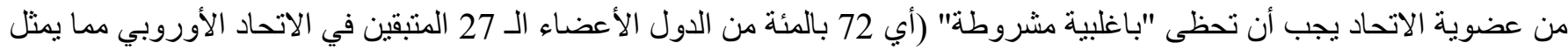

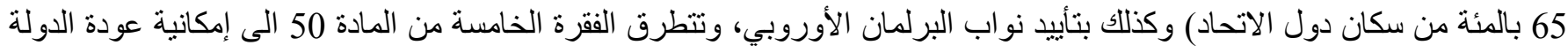

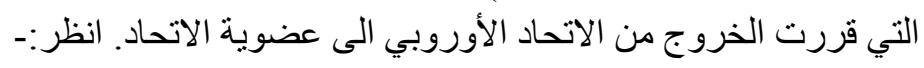

- NatCen Social Research (2019) 'Have the politicians delivered? Voters' judgement on the Brexit process', London: NatCen Social Research, available at https:/whatukthinks.org/eu/analysis/have-thepoliticians-delivered-voters-judgement-on-the-brexit-process/

- Dhingra, S. Ottaviano, G. Sampson, T. and Van Reenen, J. (2016), "The Impact of Brexit on foreign investment in the UK", Centre for Economic Performance, Paper Brexit 03, The London School of Economics and Political Science 
التصويت لمصلحة خيار الخروج بنسبة 51.9 في المئة، مقابل 48.1 في المئة، لمصلحة البقاء في الاتحاد الأوروبي 8. وعلى الرغم من أن خروج بريطانيا من الاتحاد الاوروبي هو أمر طبيعي، ذلك أن من حق الدولة الانسحاب أو الانضمام لأية منظمة منى أرادت، إلا أن المشكلة تكمن في المخاوف من انفراط عقد الاتحاد الأوروبي

\section{ثانياً: الأسباب التي تدفع باتجاه خروج بريطانيا من الاتحاد الأورويي:}

كانت هناك عدة أسباب وراء قرار بريطانيا الخروج من الاتحاد الأوروبي، يمكن استعراض أهها على النحو الآتي:

\section{1- التخلص من عبء المهاجرين واللاجئين:}

بدأ مواطنو الاتحاد الأوروبي بإثارة التساؤلات حول سياسة الباب المفتوح، بخصوص استقبال اللاجئين، وأصبحت جميع الأحزاب السياسية المختلفة في كل أرجاء أوروبا حذرة في تبني مواقف مؤيدة للاتحاد الاوروبي في مناخ مشحون بعدم التقة10. فالمواطن البريطاني يؤمن بأن الخروج من الاتحاد الأوروبي سيقلل من معدلات الهجرة الى بريطانيا بشكل ملحوظ، وسيوفر على دافعي الضرائب البريطانيين مليارات الدولارات،

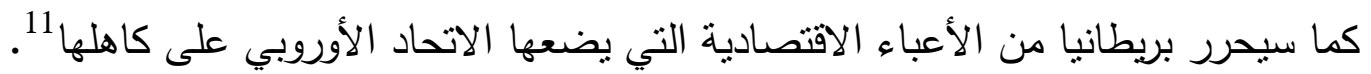

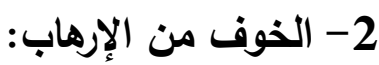

مع وصول الهجمات الإرهابية لنطال عددًا من الدول الأوروبية¹2، منلما حدث في باريس وبروكسيل، فإن أحد الإنجازات الأكثر أهمية بالنسبة للاتحاد هو حرية التتقل بين الدول، وهو الأمر الذي أصبح محل تخوف باله وشكوك من قبل مواطني الاتحاد الأوروبي 13، وفرض تحدياً كبيراً على دول أوروبا، وعمق الانقسام بين الدول الأوروبية حول إعلاء الطابع الأمني على الدور الإنساني لأوروبا تجاه اللاجئين. 3- التوفير المالي للصحة والتعليم:

8وقد تبين من خلال دراسة السلوك التصويتي للبريطانيين وجود انقساٍٍ "جيلي" بين الثباب الذين صوتوا للبقاء في الاتحاد الاوروبي بنسبة 73 في

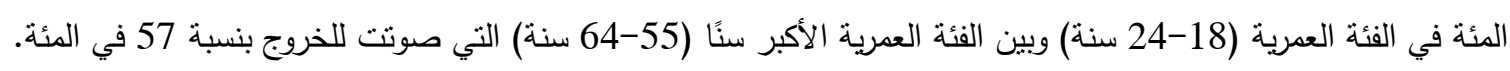

- "EU referendum: The result in maps and charts," BBC, 24/06/2016, accessed on 1/7/2019, at: http://bbc.in/28TRi57

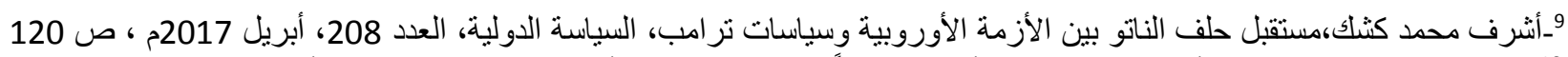

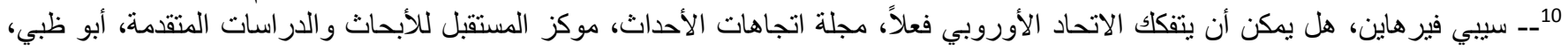

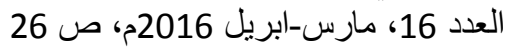

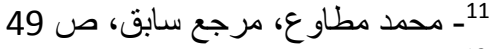

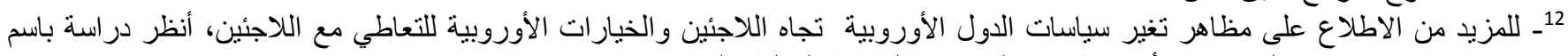

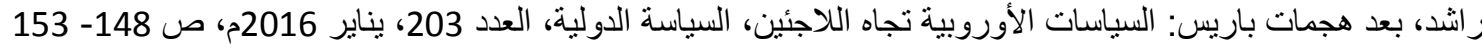

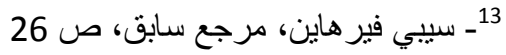


هذا السبب مترتب على التخلص من أعباء استقبال المهاجرين عبر الحدود، الذي أسهم في تصديقه مئات المطويات التي وزعت بالبريد، والتي توقعت توفير 350 مليون جنيه إسترليني (480 مليون دولار) أسبوعياً لحساب الخزينة البريطانية، وهو مبلغ كاف لبناء مستشفى. كما أن المبلغ نفسه يعادل نصف ميزانية التعليم في إنجلترا، مع اقتراحات من معسكر المعارضين للبقاء بتوظيف تلك الأموال في البحث العلمي والصناعات الجديدة.

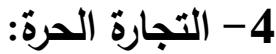

يدفع المؤيدون للخروج من الاتحاد الاوروبي بفكرة أن الاتحاد الاوروبي لم يعد مهماً لتجارة بريطانيا، كما هو الحال في السابق، وأن استمرار الازمات في منطقة اليورو، سيجعل الاتحاد الاوروبي أقل أهمية لبريطانيا. ويرى هذا الاتجاه أنه حتى في حال لم تتمكن بريطانيا من إبرام اتفاقية تجارة جديدة دع الاتحاد الأوروبي، فإن الأمر لن يكون كارثياً، لأنه سيضع بريطانيا بوضع شبيه بالولايات المتحدة الامريكية واليابان والصين، حيث يمكن لهذه الدول التصدير للاتحاد الاوروبي بسهولة ويسر، بل سيكون لدى بريطانيا الحرية في إبرام اتفاقيات تجارية مع الأسواق الاكثر نمواً في العالم مثل الصين وسينغافورة والبرازيل، من خلا منظمة التجارة العالمية 15. 5- النفوذ الدولي:

عندما يتعلق الأمر بمكانة بريطانيا في العالم، يرى المؤيدون لخروج بريطانيا من الاتحاد الأوروبي، بأن

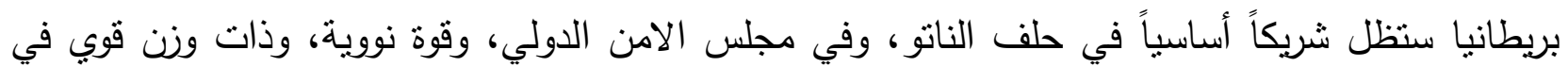

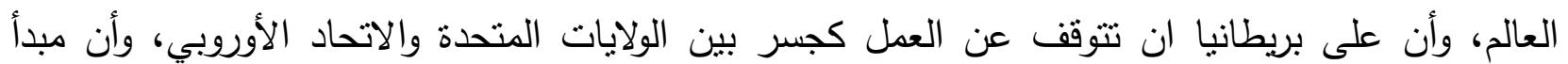
الاعتماد على الذات هو المبدأ الذي يجب أن يحكم السياسة الخارجية البريطانية مستقبلاً 16.

\section{6- الكلمة الأولى للتشريعات الوطنية:}

الناخب البريطاني أصبح على قناعة بأن الخروج من الاتحاد الأوروبي سيعلي من صوت القوانين الوطنية البريطانية، وأنه لن يكون هناك سيطرة من قبل القوانين الأوروبية الاتحادية، وهو ما سيساهم في إعادة السيطرة على قوانين النوظيف17 والخدمات الصحية والأمن. كما أن نوقعات الناخب البريطاني بمنح

\footnotetext{
${ }^{14}$ The House of Commons Library research, Brexit: impact across policy areas, Briefing Paper, Number 07213, 26 August 2016, p 14.

15 يرى الاتجاه الؤيد لخروج بريطانيا من الاتحاد أيضاً، أن تحرر بريطانيا من القو انين الأوروبية، قد يدفع بعض المستثرين الى التفكير في كونها

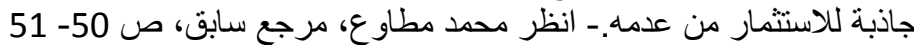

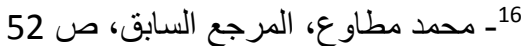
17.ـ يرى المؤيدون لخروج بريطانيا من الاتحاد الأوروبي بأن ذلك سيزيد من عدد الوظائف بثكل كبير جداً، ذلك أن الشركات البريطانية والحالة

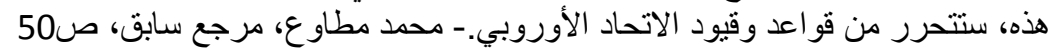


صلاحيات وسلطات أكبر للبرلمان البريطاني، جعلته يتأمل خيراً على الأصعدة كافة، خاصة أن بعض

القوانين الداخلية في حاجة إلى تغيير، لكنها تتعارض مع قوانين الاتحاد الأوروبي، ما يحول دون إقرارها. 18

\section{7- المخاوف من انضمام تركيا للاتحاد الأورويي:}

وهو الأمر الذي يتعلق بالتركيبة السكانية، فبالإضافة الى التخوف من تدفق آلاف اللاجئين، فإن غالبية سكان تركيا ينحدرون من هضبة الأناضول وينتمون لوسط آسيا، في حين تتنمي قلة بسيطة منهم لأعراق أوروبية

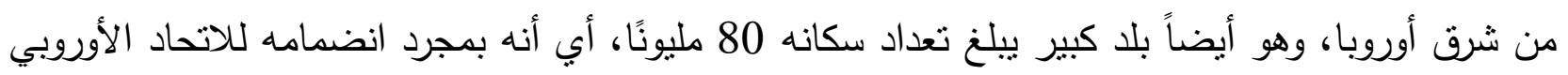
سيكون أكبر بلدان الاتحاد من الناحية السكانية، الأمر الذي سيؤدي حسب بعض الدراسات الى خلل كبير في

منظومة الاتحاد ذاتها 19.

\section{ثالثاً: موقف أيرلندا الشمالية من خروج بريطانيا من الاتحاد الأورويي:}

يعد موقف أيرلندا الثمالية ضمن الأسباب القوية، التي أجلت إعلان المملكة المتحدة خروجها من الاتحاد الأوروبي؛ فبريطانيا العظمى تتكون من اتحاد أربع دول هي إنجلترا وويلز وإسكتلندا وإيرلندا الثمالية، وبتجمع هذه الدول الأربع تحت لواء بريطانيا تتكل قوة المملكة المتحدة، ومنذ استفتاء 23 يونيو عام 2016م، حول بقاء بريطانيا

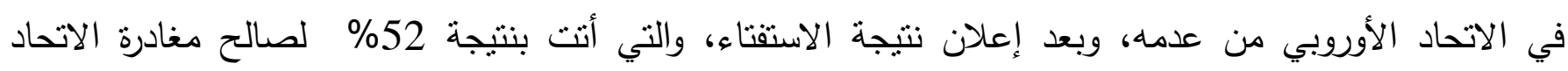
الأوروبي ، لاحت في الأفق أزمة جديدة، وهي مصير الدول الأربع حال الخروج من الاتحاد الأوروبي، فهذه الدول شهدت في أوقات مختلفة ظهور حركات انفصالية تدعو للانفصال عن بريطانيا العظمى ، ويدعم ذللك، تمتع أيرلندا الثمالية بحكومة وسلطة تتفيذية مستقلة يأتي في مقدمتها وزير أول ومجلس "و إقليم إيرلندا الثمالية هو الإقليم الوحيد الذي تفصله عن بريطانيا حدود بحرية ففي حالة انفصال بريطانيا عن الاتحاد الأوروبي، قد يحدث تفكلى للمملكة. فالحزب الوطني الأسكتلندي أصدر بياناً قال فيه إن اسكتلندا ترى مستقبلها في أوروبا، ما يشبر إلى احتمالية إجراء استفتاء آخر على مغادرة المملكة المتحدة. وبالمثل في ايرلندا حيث دعا حزب الثثين فين في أيرلندا الثمالية لإجراء استقتاء على لم الثمل الإيرلندي

\footnotetext{
${ }^{18}$ Ortiz, G. and Latorre, M.C. (2017), "Economic Impact of Potential Migration Policies in the UK after Brexit", Mimeo.

19ــ أنظر المزيد في أنس القصاص، العلاقات التركيةـ الأوروبية في ظل صعود اليمين، السياسة الدولية، العدد 208، أبريل 2017م، ص 125 وما

${ }^{20}$ Josh Hoorwitz"The UK (Leave) vote could Trigger a Wave of Exits throughout the Eu , Quartz (24June 2016) <https ://qz.com/715569/the-uk-leave-vote-could-lead-to-a-domino-of-exits-throughout-the-eu>
} 
أما الأحزاب الأيرلندية، فترى أن أيرلندا ستخسر جراء عملية الخروج أكثر من المملكة المتحدة نفسها وبناء على ذللك فأن معظم الأحزاب قامت بحملة تدعو لبقاء بريطانيا في الاتحاد الأوروبي ، بينما الحزب الاتحادي الديمقراطي

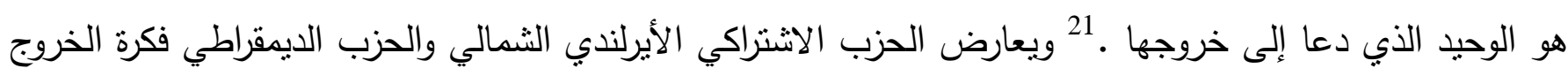

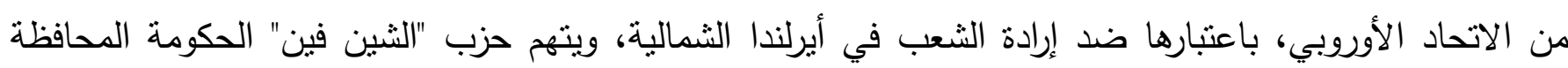
بالسعي لفرض خروج بريطانبا من الاتحاد الأوروبي على أيرلندا، ويسعى الحزب إلى وضع مكانة خاصة لأيرلندا

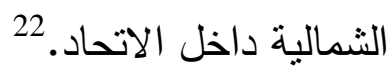

وفي تقرير صدر عن موقع ال بي بي سي عربي، بتاريخ 3 سبتمبر 2019م، ذكر أن الحزب البروتستانتي الرئيسي

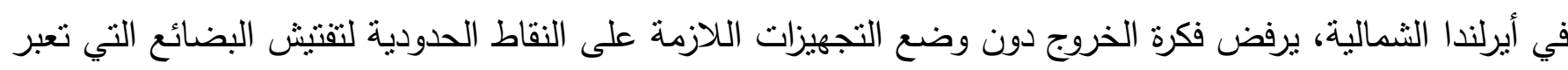
الحدود بين جزئي الجزيرتين، وهو ما يعني وضع إجراءات مميزة لإقليم إيرلندا الثمالية، مما يهدد وحدة كيان بريطانيا - العظمى

ومنذ إعلان نتيجة استقتاء 2016م، بموافقة الخروج من الاتحاد الأوروبي، ظهرت أزمة إيرلندا الثمالية، فأصبح موقفها شبه غامض ومنباين، ويعود هذا لعدة أسباب منها موقع إيرلندا المختلف عن باقي الولايات، بالإضافة إلى لـ إنى

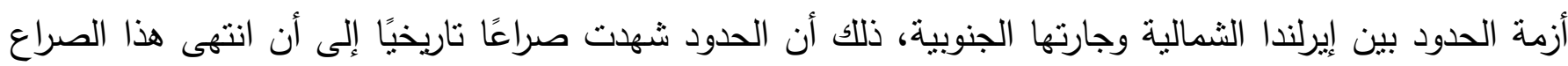
بتوقيع اتفاقية عام 1998م، والتي أدت إلى توقف الهجمات بين البريطانيين والأيرلنديين. ووفقا لهذه الاتفاقية تم فتح الحدود بين إيرلندا الثمالية والجنوبية، ونم السماح بعبور الأفراد وأصبح هناك حرية تنقل بين جزئي الجزيرة الأبرلندية تخللها مسار تعاون مشترك.

واستطاعت أبرلندا الثمالية أن تفتح سوقًا مشتركًا لمنتجاتها في أيرلندا الجنوبية، وهو ما ترتب عليه عبور يومي من الثمال إلى الجنوب، فالحدود بينهم هي حدود برية ممتدة بطول 500كم، و يشق هذه الحدود ما يقارب 200 طريق بري. وفي حالة خروج بريطانيا فأن أزمة الحدود قد تظهر مرة أخرى ، فقد كانت المباحثات بين بريطانيا ودول

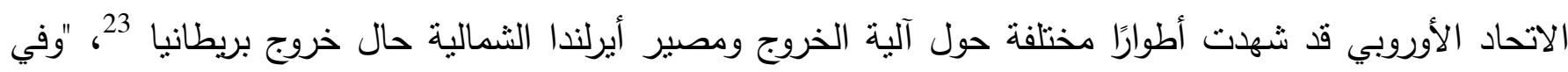
الـ25 من نوفمبر لعام 2018م، نوصل رؤساء الدول والحكومات الأوروبية إلى اتفاق ينص على تحول إيرلندا الثمالية إلى منطقة جمركية واحدة، تبقى فيها حرية عبور السلع المسموح بها من الاتحاد الأوروبي دون تطبيق أية رسوم

21 ${ }^{21}$ ـوار هاثم، خروج بريطانيا من الاتحاد الأوروبي : دراسة في الأسباب والتداعيات "العستقبل العربي ": مركز دراسات الوحدة العربية ، عدد

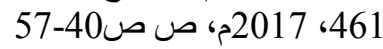

22 General Election 2017: where uk,s parties stand on Brexit "BBC News 925April2017" (http://www.bbc.com/news/uk-politics-39665835) https://alkhaleejonline.net/، 23 تداعيات قاسية بانتظار بريطانيا بعد خروجها من الاتحاد الأوروبي، الخليج أونلاين، 
جمركية. وهذا الاتفاق لا يعد الأمتل لبريطانيا لأنه سيمنع بريطانيا من حرية التوقيع على اتفاقية تجارية لحرية تبادل

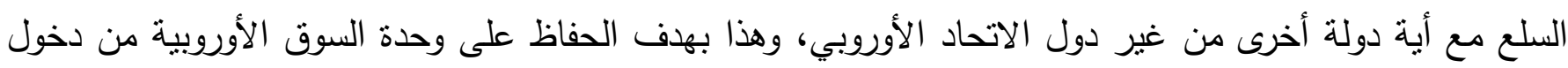

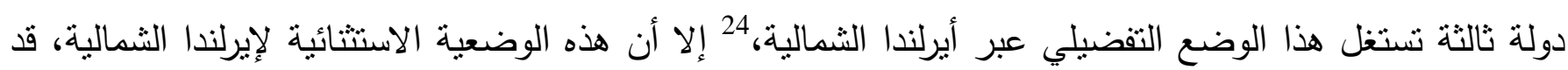
تأني بنتائج غير مرضية قد تهدد وحدة المملكة المتحدة. وقد تم رفض هذه الاتفاقية من قبل فهذه الاتفاقية رفضها البرلمان البريطاني وهو ما دفع مجلس العموم البريطاني في 15 يناير 2019م، للتصويت على رفض اتفاقية الخروج

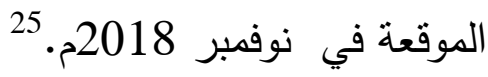

إن اتفاقية خروج بريطانيا من الاتحاد الأوروبي، تضع إيرلندا الثمالية في مرمى النيران ، ففي حالة الوصول الى اتفاق استثنائي يجعل إيرلندا الثمالية تحتفظ بحرية التنقل بينها وبين الجزء الجنوبي من الجزيرة الإيرلندية، فإن تيار الانفصالين سيجد الفرصة لتحقيق حلم الانفصال عن بريطانيا، وهو ما عبر عنه الحزب الجمهوري بأيرلندا الثمالية عام 2018 عندما دعت ميشيل أونيل لإجراء استفتاء بشأن الانفصال عن المملكة المتحدة. ويسعى انصار الانفصال عن بريطانيا إلى جعل إيرلندا الثمالية دولة مستقلة يحق لها الدخول في الاتحاد الأوروبي أو الاندماج مع إيرلندا الثماليةK وهذا ما تخشاه بريطانيا وهو ما جعلها تتأخر في إعلان الانفصال الرسمي عن الاتحاد الأوربي.26 وفي حالة العودة إلى الحدود الصلبة بين جزئي الجزيرة الإيرلندية، فربما تعود الأحداث الدموية مرة أخرى والعودة

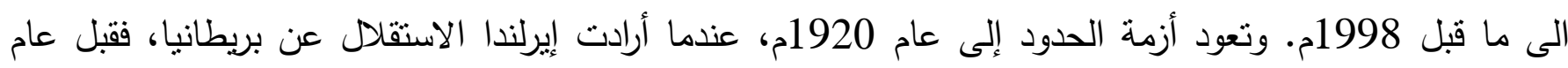
1920م، كانت إيرلندا تابعة للملكة المتحدة حتى اندلعت الحرب بين إيرلندا وبريطانيا فيما عرف بحرب الاستقلال واستمرت هذه الحرب قرابة العامين حتى نالت إيرلندا استقلالها عن بريطانيا وأصبحت دولة مستقلة ذات سيادة عام

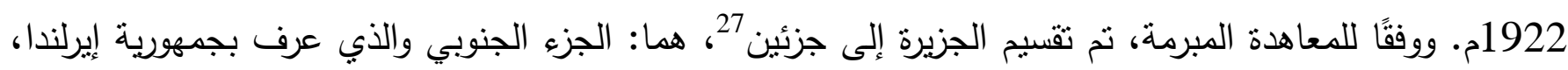
والجزء الثمالي الذي رفض هذا الاستقلال وقرر الاستمرار تحت حكم التاج البريطاني.

نصت المعاهدة على تمتع إيرلندا الثمالية بحكم ذاتي، وبعد انضمام إيرلندا الثمالية للملكة المتحدة ظهرت أزمة تقسيم الحدود بين الثمال والجنوب، والتي ظلت مستمرة حتى عام 1998م، حتى تم التوصل الى اتفاق عرف فيما بعد باتفاق بلفاست، والذي حول الجزيرة الإيرلندية إلى كيان موحد اقتصادياً، ومنح مواطني أيرلندا الثمالية الحق في ازدواج

24_ الحدود الإيرلندية ..معضلة تاريخية تهدد وحدة وسلام المملكة المتحدة موقع الخليج أونلاين

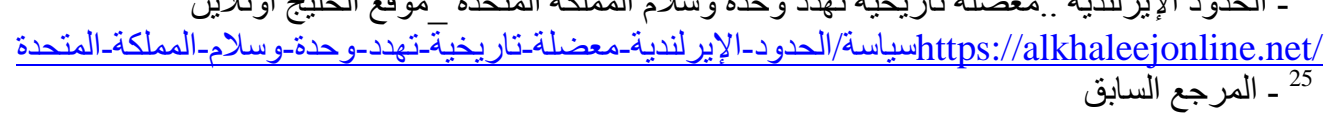
${ }^{26}$ Armstrong, K. (2018) 'Regulatory alignment and divergence after Brexit', Journal of European Public Policy. doi: 10.1080/13501763.2018.1467956

${ }^{27}$ Ericson, A. (2018) 'Is Theresa May a bad negotiator, or is Brexit just an impossible proposition? Answer: yes', Washington Post, 14 December, https://wapo.st/2FxzVTB. 
الجنسية بين بريطانيا وإيرلندا في وقت واحد، وكذلك الحق في تقرير المصير والانفصال عن المملكة المتحدة28، مع وجود حرية انتقال حر للسلع والمنتجات، وحرية نقل رأس المال وكان هذا يقع ضمن اتفاقيات العضوية للاتحاد الأوروبي.

وفي حالة انفصال المملكة المتحدة، فهنالك صعوبة في استمرار هذا الوضع، وسيصبح هناك رسومًا جمركية بين البلدين، علاوة على قيود حركة المواطنين في حالة التتقل بين الثمال والجنوب، وهذه القيود كانت مختفية بين جزئي الجزيرة وقت الانضمام للاتحاد الأوروبي. ونظراً للنشاط التجاري المنسع بين شطري الجزيرة فأن ظهور مثل هذه القيود ستؤثر بشكل كبير على مستقبل المواطنين الاقتصادي في أيرلندا الثمالية، وهو ما قد يدفع إلى نشأة النزاع مرة أخرى بين الثمال والجنوب وربما يؤدى إلى ظهور الحركات الانفصالية الني تدعو إلى الاندماج مع جمهورية أيرلندا. 29

\section{رابعاً: موقف ويلز من خروج بريطانيا من الاتحاد الأوروبي:}

على الرغم من أن ويلز لم يظهر بها أي احتمالية لحدوث انفصال عن المملكة المتحدة، إلا أن الحزب القومي ״بلايد كامريه (أي حزب ويلز) ينادي بالاستقلال منذ إنشائه عام 1925م. والدليل على غياب النزعة الانفصالية عند معظم أهالي ويلز ، أن الحزب لا يملك إلا 10 مقاعد من أصل 60 مقعدًا في البرلمان المحلي 30. غير أن الوضع قد يتغير في ظل الأزمة الحالية، وقد سمع رئيس الوزراء بوريس جونسون من رئيس وزراء ويلز مارك درايفورد، المنتمي إلى حزب العمال، أن "بريكسته سيكون كارثياً. ورغم أنه من المستبعد أن تظهّر اندفاعات انفصالية في ويلز ، إلا أن أن المقاطعة لا بد أن تتأثر بالاتجاهات السلبية التي ستحصل حولها، خصوصاً في اسكوتلندا وأيرلندا الثمالية لقد شهدت مقاطعة ويلز في منتصف مايو 2019م، مظاهرات مطالبة بالاستقلال، وعلى الرغم من موقف ويلز الداعم لاتفاقية البريكسيت، إلا أن هذه المظاهرات الداعمة للانفصال عن بريطانيا تظهر مدى تتاقض الموقف الويلزي.

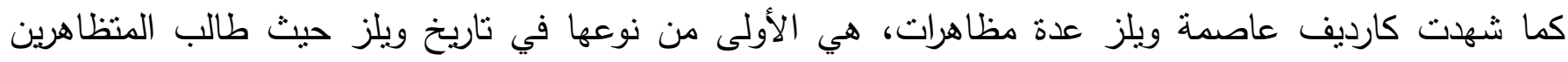

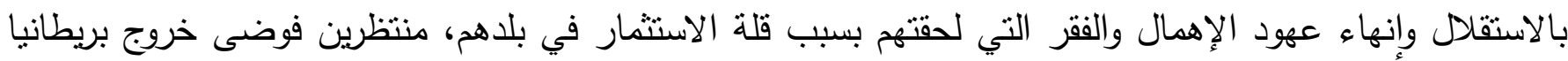

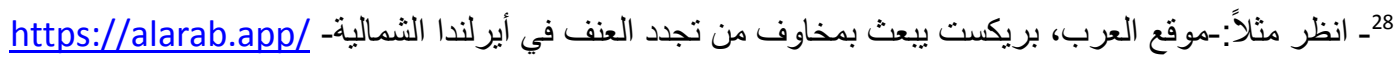
${ }^{29}$ Gamble, A. (2019) 'The realignment of British politics in the wake of Brexit', The Political Quarterly 90 (2): $177-86$.

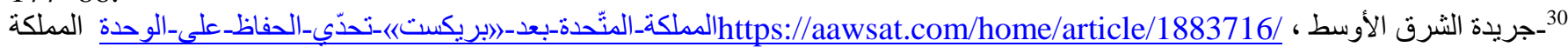
المتّحدة بعد (ابريكست)|... تحدّي الحفاظ على الوحدة

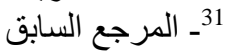


من الاتحاد الأوروبي ، ومعتقدين أن مستقبل ويلز سيكون أفضل عندما تصبح ويلز دولة مستقلة خارج المملكة

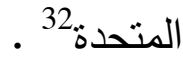
ومن الناحية العملية، فإن مسألة استقلال ويلز، هي قضية شائكة، ذلك أنها لا تحظى بدعم كامل من الثعب الويلزي، فالغاليية ما زالت تفضل أن تكون جزءًا من المملكة المتحدة، نظرًا لانخفاض المستوى الاقتصادي في ويلز و"وفقا للتقرير الصادر عن مؤسسة جوزيف راونتري في عام 2016م، أن ربع الأثخاص في ويلز يكافحون من أجل تغطية نفقاتهم وأن الفقر يكلف البلاد 3.6 مليار جنيه إسترليني سنويًا وتكمن المشكلة الرئيسية في توافر فرص العمل، ففي سبتمبر 2016م، كان حوالي 17٪ من العاملين بدوام جزئي لم يتمكنوا من الحصول على وظائف بدوام كامل، وفي بلاينا جوينت ، فإن عدد الوظائف لكل فرد هو نصف المتوسط في بريطانيا. وفي حالة خروج بريطانيا من الاتحاد الأوروبي ، سيتم تجريد ويلز من تمويلها الهيكلي للاتحاد الأوروبي، وهذا من المرجح أن يغرق البلاد في المزيد

$$
\text { من المصاعب الاقتصادية }
$$

وبالعودة إلى العلاقة التاريخية بين ويلز والمملكة المتحدة، نجد أن الخطاب الفئوي الداعي إلى انفصال ويلز، لا يجد صديً كبيرًا في المجتمع الويلزي، إلا أن اتفاقية البريسكت قد تثير بعض النزاعات العرقية، فاختلاف اللغة والتاريخ والثقافة قد يؤثر على العلاقة مع المملكة المتحدة، بالإضافة الى أن توقف أرباح الاتحاد الأوروبي إلى ويلز ، وتداعيات خروج بريطانيا من الاتحاد الأوروبي، ستؤثثر على الوضع الاقتصادي في ويلز . ومن التحديات التي تهدد بقاء ويلز في المملكة المتحدة حال تتفيذ البريكسيت، أنه وعلى الرغم من تصويت 52\% من سكان ويلز على القبول لتنفيذ اتفاقية البريكسيت، فإن هذا لا يعني بالضرورة بقاء ويلز مع المملكة المتحدة حال الخروج من الاتحاد الأوروبي، فدعوات حزب وبلز plaid cymru الداعية للانفصال عن بريطانيا، مازالت أصداؤها تتردد في ويلز ، وذلك على الرغم من مرور عشرين عامًا عليها. كما أن مسألة الاستقال لها أبعاد عديدة من الناحية الاجتماعية والاقتصادية، فالمعارضون للانفصال يرون أن ويلز دولة صغيرة وفقيرة بحيث لا تستطيع أن تنق وحدها على المسرح العالمي؛ بينما الحملات المؤيدة للاستقال ترى أن هذا غير واقعي، فهنالك 18 دولة في أوروبا أصغر من ويلز ؛ وتنتطيع إدارة شؤونها دون الحاجة إلى دول أخرى.

إن التحول الدستوري في سلطة المملكة حال خروج بريطانيا من الاتحاد الأوروبي، سيؤدي الى ظهور احتمالات

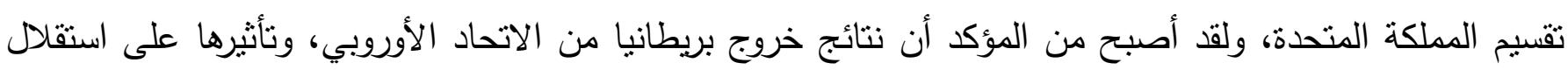

\footnotetext{
32 Thousands march in Cardiff calling for Welsh independence - The Guardian-from : https://www.theguardian.com/uk-news/2019/may/11/thousands-march-in-cardiff-calling-for-welsh-independence 33 It's time for Wales to start talking about independence- The Guardian-from : https://www.theguardian.com/commentisfree/2017/mar/14/wales-independence-leave-uk-scotland
} 
ويلز ، تتوقف الى حذ كبير للغاية على تصرفات رئيس الوزراء، وبالعودة الى قراءة معقةة لتصريحات بوريس جونسون

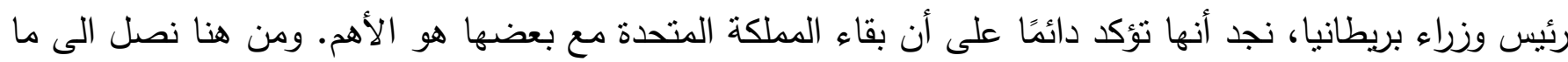
يشير الى أنه في حالة خروج بريطانيا من الاتحاد، دون تحديد للعلاقة مع ويلز ، مضافًا إلى ذلك تصاعد تيار الاستقلال في ويلز، فإنه سيكون من الصعب على جونسون تجاهل حق الثعب في تقرير المصير. 34 خامساً: موقف اسكتلندا من خروج بريطانيا من الاتحاد الأورويي: تظهر مشكلة الاستقلال ضمن الأزمات التي يخشى ظهورها حال خروج بريطانيا من الاتحاد الأوروبي، فتاريخ العلاقات بين دولة اسكتلندا والمملكة المتحدة منذ إعلان انضمام اسكتلندا لبريطانيا العظمى مليء بالحركات التي

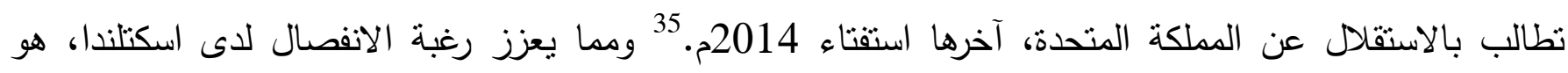
مساهمة اسكتلندا بنسبة تقارب الـ10\% من اجمالي اقتصاد المملكة المتحدة، وذلك بفضل الثروة النفطية التي تملكها اسكتلندا. وعلى الرغم من هذه الثروة النفطية التي يزخر بها بحر الثمال والتي بنى عليها الحزب القومي الاسكتلندي حملته الأولى للاستقلال عام 2014م، فإن اسكثلندا حال استقلالها ستواجه مصاعب اقتصادية كبيرة، وترجع هذه المصاعب إلى أن معظم صادرات اسكتلندا تذهب إلى جميع دول المملكة المتحدة، مما بعني أن نسبة البطالة قد ترتفع في البلاد.

لقد شهد عام 2014م، استفتاء اسكتلندا حول انفصالها عن بريطانيا، وكانت أسباب دعاة الاستقلال تعتمد على استغلال إنجلترا لخيرات بلادهم تحت مسمى الوحدة، لكن هذا الاستفتاء لم يجد ضالته عند الاسكتلنديين وجاءت النتيجة رافضة للانفصال، ولتسدل الستار على قضية أرقت وحدة المملكة المتحدة، ولتطمئن معها حكومة المملكة أن قضية الانفصال قد انتهت 37.

ولكن ظهور استفتاء انفصال المملكة المتحدة عن الاتحاد الأوروبي، أعاد قضية الاستقل الى الظهور مرة أخرى 38، وأكثر ما يخشاه سكان اسكتلندا هو تكريس المعاناة الاقتصادية حال تتفيذ البريكسيت في 31 أكتوبر 2019م، فالحزب القومي الاسكتلندي لطالما وعد بالإبقاء على اسكتلندا داخل الاتحاد الأوروبي. والمفارقة أنه في هُه الوقت الذي قد تخرج فيه بريطانيا من الاتحاد الأوروبي"، فإن دولة مستقلة (اسكثلندا المستقلة) قد تكون تتفاوض في

${ }^{34}$ Henderson, A., Jeffrey, C., Wincott, D. and Wyn Jones, R. (2017) 'How Brexit was made in England', The British Journal of Politics and International Relations 19 (4): 631-46.

${ }^{35}$ ennings, W. and Lodge, M. (2019) 'Brexit, the Tides and Canute: the fracturing politics of the British State', Journal of European Public Policy 26(5): 772-789.

${ }^{36}$ Working Paper: Border controls on cross border trade in goods, Point 24, NI Department for the Economy, May 2017 - Retrieved via Martina Anderson MEP

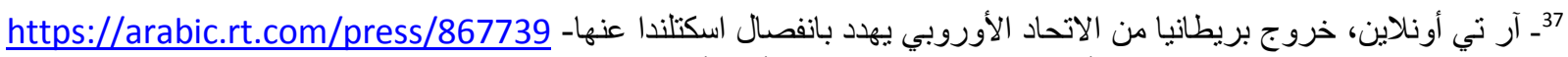

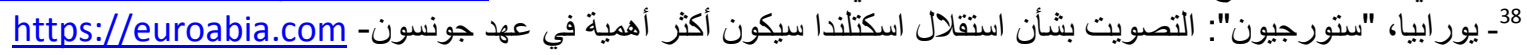


نفس الوقت حول شروط عضويتها في الاتحاد الأوروبي". إذن فكلما كانت احتمالات خروج بريطانيا وشيكة، كلما زادت احتمالية أن بطالب الحزب القومي الاسكتلندي بإجراء استفتاء ثان باستقلال اسكتلندا، بل أن احتمال حصوله على أغلبية في تزايد، خاصة وأن الانتماء الى الاتحاد الأوروبي والدخول الى السوق الأوروبية الموحدة، هما من ركائز خطط استقلال اسكتلندا عن بريطانيا

لقد طالبت الزعيمة الاسكتلندية نيكولا ستورجيون، في منتصف ابريل من عام 2019م، بضرورة إجراء استفتاء جديد حول استقلال اكتلندا عن المملكة المتحدة، بحلول عام 2021م، إذا ما غادرت بريطانيا الاتحاد الأوروبي، وذلك رغم الاعتراف بأنها تفتقر إلى القوة اللازمة لتحقيق ذلك بمفردها. كما أبلغت البرلمان الأسكتلندي في إدنبرة، أنه إذا غادرت بريطانيا الاتحاد الأوروبي، "يجب تقديم خيار بين خروج بربطانيا من الاتحاد الأوروبي ومستقبل اسكتلندا كدولة أوروبية مستقلة في عمر هذا البرلمان" - قبل الانتخابات الاسكتلندية القادمة، في مايو 2021م، وتتير ستورجيون إلى تقديم تشريعات تحدد إطار الاستفتاء الجديد، إلا ان إجراء منل هذا التصويت سيحتاج إلى مواققة من الحكومة البريطانية، التي تقول إن الوقت غير مناسب. 40

ويبدو أن موقف الاتحاد الأوروبي تجاه استقلل اسكتلندا، سيكون متغيرًا حال خروج بريطانيا من الاتحاد الأوروبي، فالمؤشرات توضح تعاطف الاتحاد الأوروبي مع الدول التي تسعى لعضويته، وهو ما سيجعل طلب إسكتلندا للانضمام يمر دون أية تعقيدات، وهو ما سيجعل بريطانيا ايضًا تعيش في فوضى سياسية غير معلومة الوجهة.

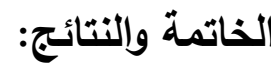

إن خروج بربطانيا من الاتحاد الأوروبي، يؤدي بنا إلى استتناج مفاده بأن المشروع الأوروبي بعيد عن الاستقرار، حيث سيؤدي هذا الخروج إلى زعزعة توازن قائم منذ فترة طويلة، وهو ما سمح بالحفاظ على سلامة المجتمع الأوروبي على الرغم من المصالح المتعارضة في كثير من الأحيان للدول الأعضاء بالاتحاد. ويُعتقد بأن السبب الرئيسي وراء خروج بريطانيا من الاتحاد الأوروبي ينبع إلى حد كبير من فنل الدول الأعضاء في الاتفاق على أسس وأولويات مشتركة، خاصة فيما يتعلق بنموذج التكامل واعتماده، وهذا ينطبق على كل من العقيدة السياسية ونموذج التكامل الاقتصادي. 
وأيضًا فإن الانفصال عن الاتحاد الأوروبي، قد يشكل بعضيًا من الآراء والاتجاهات لدى كل من ويلز وايرلندا الثمالية واسكتلندا، في محاولة التفكير بالانفصال عن المملكة المتحدة، وهو ما يثبت صحة الفرضية التي انطلقت

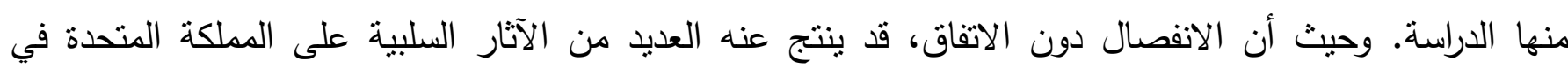
مختلف المجالات، فقد خلصت الدراسة لمجموعة من النتائج:

1- كان لظهور نتائج استقتاء يونيو 2016م، تداعيات سياسية واقتصادية مباشرة، من أهمها استقالة ديفيد

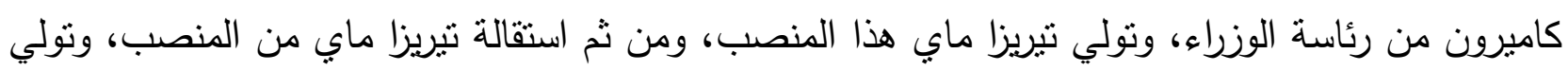

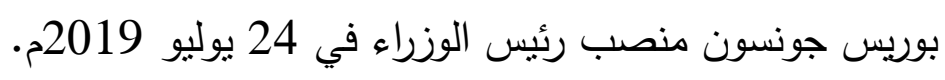
2- من المتوقع أن يكون هناك سيناريوهات سياسية في المدى المتوسط والبعيد، تتمتل في تفكك المملكة المتحدة والاتحاد الأوروبي. 3- في الفترة المقبلة في شأن المفاوضات حول خروج بريطانيا عن الاتحاد الأوروبي، سوف تمتد تلك المفاوضات في شأن الانفصال لفترات طويلة. 4- كلًا من ويلز واسكتلندا وايرلندا الثمالية، ستستثمر تلاك الفترة، في محاولة البعض منهم للانفصال عن المملكة المتحدة، الأمر الذي سيتمضر عنه نتائج قد تقيد البعض وقد تضر البعض الآخر . 


\section{References:}

First: Arab references

.1Nawar Hashem, Britain's Exit from the European Union: A Study of Causes and Implications, Center for Arab Unity Studies, No. 461, 2017

.2Sebie Verhayn, Can the European Union Really Disintegrate, Journal of Trends in Events, Future Center for Research and Advanced Studies, Abu Dhabi, No. 16, March-April 2016

.3Ashraf Mohamed Kishk, NATO's Future Between the European Crisis and Trump's Politics, International Politics, No. 208, April 2017

.4Anas Al-Qassas, Turkish-European Relations in the Shadow of the Right, International Politics, No. 208, April 2017

.5Muhammad Mutawa, Exit and Survival Challenges: The Complexities of the Relationship Between Britain and the European Union, International Politics, No. 203, January 2016.

.6Basem Rashid, after the Paris attacks: European policies towards refugees, international politics, No. 203, January 2016

.7Maya Gridini: "What are the implications of Britain's exit from the European Union?" Site:

]www.alarabiya.net], June 26, 2016 CE

.8Irish borders ... a historical dilemma threatening the unity and peace of the United Kingdom Gulf Online website

https://alkhaleejonline.net/ Irish politics / borders-historical-dilemma-threatening unity-and-peaceUnited Kingdom

9Severe repercussions awaiting Britain after its exit from the European Union, Gulf Online, https://alkhaleejonline.net/

.10RT Online, Britain's Exit from the European Union Threatens to Secede Scotland from it https://arabic.rt.com/press/867739

.11Europe, "Sturgeon": Voting for independence for Scotland will be more important in Johnson's reign - https://euroabia.com

- .12See for example: - The Arabs website, Brexit raises fears of renewed violence in Northern Ireland - https://alarab.app/

.13Al-Sharq Al-Awsat Newspaper, https://aawsat.com/home/article/1883716/ The United Kingdom - after - "Brexit" - the challenge - the preservation - of unity - The United Kingdom after "Brexit" ... the challenge of preserving unity 
1. Dąbrowski, M. (2016). The future of the European Union: towards a functional federalism. Acta Oeconomica, 66(1). doi:10.1556/032.2016.66.S1.2.

2. David Cameron, "EU speech at Bloomberg," Bloomberg, 23/01/2013, accessed on 30/6/2016, at: http://bit.ly/LBzZU4

3. Stern, S. (2018) 'Theresa May's handling of Brexit is a classic case of bad leadership', The Conversation, 12 December, available at https://theconversation.com/theresa-mays-handling-ofbrexit-is-a-classic-case-of-bad-leadership-108646.

4. Clausing, K.A. and Dorobantu, C.L. (2005), "Re-entering Europe: Does European Union candidacy boost foreign direct investment?", The Economics of Transition. Vol.13, No1.

5. "EU referendum: The result in maps and charts," $B B C, 24 / 06 / 2016$, accessed on 1/7/2019, at: http://bbc.in/28TRi57

6. Nat Cen Social Research (2019) 'Have the politicians delivered? Voters' judgement on the Brexit process', London: NatCen Social Research, available at https://whatukthinks.org/eu/analysis/havethe-politicians-delivered-voters-judgement-on-the-brexit-process/.

7. Dhingra, S. Ottaviano, G. Sampson, T. and Van Reenen, J. (2016), "The Impact of Brexit on foreign investment in the UK", Centre for Economic Performance, Paper Brexit 03, The London School of Economics and Political Science.

8. The House of Commons Library research, Brexit: impact across policy areas, Briefing Paper, Number 07213, 26 August 2016

9. Ortiz, G. and Latorre, M.C. (2018), “A computable general equilibrium analysis of Brexit: Barriers to trade and immigration restrictions", Mimeo.

10. Josh Hoorwitz"The UK (Leave) vote could Trigger a Wave of Exits throughout the Eu , Quartz (24June 2016) <https ://qz.com/715569/the-uk-leave-vote-could-lead-to-a-domino-of-exitsthroughout-the-eu>

11. General Election 2017: where uk,s parties stand on Brexit "BBC News 925April2017" (http://www.bbc.com/news/uk-politics-39665835)

12. Armstrong, K. (2018) 'Regulatory alignment and divergence after Brexit', Journal of European Public Policy. doi: 10.1080/13501763.2018.1467956

13. Ericson, A. (2018) 'Is Theresa May a bad negotiator, or is Brexit just an impossible proposition? Answer: yes', Washington Post, 14 December, https://wapo.st/2FxzVTB.

14. Gamble, A. (2019) 'The realignment of British politics in the wake of Brexit', The Political Quarterly 90 (2)

15. Thousands march in Cardiff calling for Welsh independence - The Guardian-from : https://www.theguardian.com/uk-news/2019/may/11/thousands-march-in-cardiff-calling-forwelsh-independence

16. It's time for Wales to start talking about independence- The Guardian-from : https://www.theguardian.com/commentisfree/2017/mar/14/wales-independence-leave-uk-scotland

17. Henderson, A., Jeffrey, C., Wincott, D. and Wyn Jones, R. (2017) 'How Brexit was made in England', The British Journal of Politics and International Relations 19 (4): 631-46.

18. ennings, W. and Lodge, M. (2019) 'Brexit, the Tides and Canute: the fracturing politics of the British State', Journal of European Public Policy 26(5): 772-789.

19. Working Paper: Border controls on cross border trade in goods, Point 24, NI Department for the Economy, May 2017 - Retrieved via Martina Anderson MEP

20. Scottish Leader Calls for Independence Referendum if Britain Leaves the E.U.- The New York Times- https://www.nytimes.com/2019/04/24/world/europe/scotland-independence-referendumbrexit.html 
